\title{
Innovative Concepts on the Governance System of Ecological Civilization
}

\author{
Yaping Mao, Rui Sun \\ School of Marxism, Kunming Metallurgy College, Kunming, Yunnan Province, China
}

Keywords: ecological civilization, governance system, innovative concepts.

\begin{abstract}
For human beings, ecological civilization is the reflection of industrial civilization. Under the background of reform and opening-up, a large quantity of ecological resources have been consumed in China through the economic and rational production methods and life styles; ecological rationality has become a hot issue. This paper discusses the importance of ecological civilization from the perspective of social change, and puts forward to some ideas on the innovate mechanism of ecological civilization governance.
\end{abstract}

\section{Introduction}

In the history of human civilization, ecological civilization comes after the primitive civilization, the agricultural civilization and the industrial civilization; it is the advanced form of human civilization. Ecological civilization requires the harmony between man and nature, and the combination of nature and civilization. Karl Marx once pointed that, "nature is the inorganic body of human beings; men live on nature... and is a part of the nature. " In the stage of industrial civilization, human beings conquered the nature through various technical means, in order to meet their own development requirements. But the over extraction of natural resources comes together with great material achievements. The huge scale of industrial development leads to the irrevocable loss of nature's self-repairing ability, and endangers the survival and development of mankind. In the mid and late Twentieth Century, people began to reflect on the profound lessons brought by traditional industrial civilization, and put forward to the concept of ecological civilization. At present, ecological civilization has become a inevitable trend of the entire human society.

\section{The Decisive Role of Social Changes on the Overall Trend of Ecological Civilization in Society}

Traditional economists believe that, environmental protection will increase production costs and reduce the competitiveness of enterprises. But the long history of social development has proved the "Porter Hypothesis": environmental protection can stimulate technological innovation, thus help enterprises to reduce costs, improve product qualities and enhance market competitiveness. The construction of ecological civilization provides new impetus for the advancement of social civilization. Now the concept has been accepted by the society.

\subsection{Changes in the allocation of ecological resources since the reform and opening up.}

Resources are materials which can satisfy the utility needs of human beings; they occupy the center position in human production activities. Resource allocation means to combine and recombine various resources according to a certain proportion, then produce and provide a variety of products and services to meet the requirements of different social components on economic activities. There is always a contradiction between the limited resources and the unlimited human requirements. In the context of economic globalization, that contradiction is becoming increasingly prominent. Since the reform and opening up of China, market economy has taken the responsibility of resource allocation. The market can distribute resources efficiently. But in this process, all the resources, including ecological resources, are materialized. Main market players are driven by the pursuit of maximizing their own interest. In order to gain profit, they extract resources and expand production scales to the 
largest extent, which cause the extreme expansion of production and consumption scales. Natural resources are over exploited, since natural conditions are not included in the production cost. The excessive pursuit of GDP growth and neglect on environmental protection lead to the extreme tension between human and nature. If this situation cannot be changed, the market economy will be in a difficult situation. Under the rigid constraint on resource exploitation and environment protection, it is urgent to change the way of development, since the traditional development mode is unsustainable. The new development approach must reflect the ideological concept and the value orientation of ecological civilization; we need to emphasize the market economy as well as the ecological environment protection at the same time, saving resources and using them intensively, so as to establish a harmonious relationship between human and nature and realize the sustainable development.

\subsection{Changes in social class since the reform and opening up.}

Before the reform and opening up, the social stratum structure in China was relatively single. Main social classes are the peasantry class, the working class and the intellectual class. With the establishment of market economy after the reform and opening up, specialized labor division leads to the subdivision of traditional three social classes. A new social stratum structure has been formed in which the working class plays the leading role while other flourishing new-rising social stratum develop side by side. The profound adjustment of social interest structure brings a large number of interest conflicts and demands.

The reform and opening up undertaking in China achieves great success, since it complies with the expectations of every social members on pursuing material interests. The institutional innovation which allows some people to get rich first inspires the enthusiasm of all people to become rich. Without regard to the ecological environment cost, each individual in the society has benefited greatly from the reform and opening up. The market mechanism of selecting the superior and eliminateing the inferior results in the widening gap of material interests. Currently, the purposes of ecological civilization transformation are allocating social wealth with justice and reasonability, narrowing the income gap and restoring the ecological environment. During the construction of ecological civilization, some people will lose a part of their interests. This group of people takes the dominant position in the society; they may oppose the ecological civilization transformation and reform because they will lose vested interests in that process. So they have to establish cultural consciousness of carrying forward social justice, taking on the responsibility of ecological environment protection, and maintaining the sustainable and stable development of economy and the society.

\subsection{Changes in social psychology since the reform and opening up.}

Since the reform and opening up, with the diversification of social and economic components, material benefits, life styles and employment modes, people's thought are becoming more and more independent and diversified. In the transition from planned economy to market economy, the ideology of citizens has changed from collectivism and equalitarianism to the pursuit of maximizing individual interests. The egoism of "economic man" has been highlighted and then generalized to the field of "social man". Because of the differences in labor division, social position, interest pursuit and educational level, people's values and criteria vary greatly; social consciousness is becoming increasingly diversified. Some scholars point out that, environmental attitude varies by social stratum. The ruling elite class, the old middle class and the new social stratum oppose environmentally unfriendly behaviors more fiercely than individual households and the working class. The new social stratum oppose environmentally unfriendly behaviors more fiercely than the old middle class. The progress of social development does not alleviate ecological crisis, but makes a more urgent appeal for environmental improvement. 


\section{Problems in the Ecological Civilization Construction and Ecological Environment Management}

\subsection{Structural problems in the construction of ecological civilization.}

The traditional disciplines of economy and ecology do not overlap. It is a new topic to integrate the two subjects in social development. Traditional economists concerned production, circulation, distribution and consumption; ecological resources which play the role of assistance and utilization were regarded as inexhaustible. But nowadays, the limitation of ecological resources on economic activities is becoming increasingly prominent; the two factors need to be integrated. The institutional construction of ecological civilization involves the promotion of ideology, the perfection of legal system and the improvement of ecological protection rules and standards. Economic, political, cultural and social factors should be promoted together to put the whole system construction into practice. However, ecological resources has been regarded as public resources for a period of long time. The "free ride" overflow effect is serious; the "property rights" of ecological resources are not clearly stipulated; market players only pursue for their own interests. Due to these objective reasons, ecological environment protection does not only involve scientific and technological methods, but also relate to all aspects in social civilization construction. The issue of ecological environment protection should be lifted to the height of national strategy, in order to be integrated into the overall economic and social development of China and solve environmental problems effectively.

\subsection{The absence of integral policy on ecological environmental management.}

For many years, the principal contradiction in our country is the contradiction between the ever-growing material and cultural needs of the people and the backwardness of social production. To solve this contradiction, system construction is superior to other aspects of economic construction; ecological civilization construction is not promoted effectively. The economic development mode characterize by high investment, high consumption, high pollution and low efficiency causes different degrees of environmental damage. In addition, in the past, GDP growth is the only index of national economic statistics, and the only standard in cadre appointment and assessment mechanism, which leads to the overexploitation of natural resources in some places. At the same time, the government does not invest sufficient fund on environmental protection; environmental protection laws are also missing. Karl Marx pointed that, "people will feel it again, and recognize the consistency between themselves and the nature...But to realize the regulation, only recognition is not enough. The regulation requires a complete change in existing production mode and in the whole social system which is connected with the production mode." In the process of industrialization, the old ecological system in China should be deconstructed to complete the construction of a new system. It is a resource game involving many parties. "In order to coordinate the relationship between human and natural ecosystems, human society should undergo profound changes. The cause of these changes lies in ecology, but the changes are about society and economy; the key of realizing these changes lies in politics. "

\section{Strengthening the Overall Development of Policies and Promote the Construction of Ecological Civilization}

Ecological civilization is the idea of respecting nature, conforming to nature and protecting nature. Human's progress in politics, economy, culture and ecology can be seen as a component of civilization. On one hand, the equal and mutual benefit relationship between man and nature indicates that without ecological security, human beings will be in serious survival crisis. On the other hand, as the main body of ecological civilization, human beings must internalize the content and requirements of ecological civilization in our legal systems, ideological consciousness and social norms, and take it as a basic standard which measures the degree of human civilization. At this level, the socialist material civilization should include the balanced development of social economy and natural ecology; 
the socialist political civilization reform should include policies and regulations on ecology protection, and tries to realize the harmonious coexistence between man and nature; the socialist spiritual civilization should take the ideology of ecological environment protection into consideration. This requires the government to put ecological civilization construction on the agenda.

\subsection{Innovate the overall social policy and promote the construction of ecological civilization.}

The construction of ecological civilization is not only about ideological and theoretical discussions, but also relates to the transformation of social system in practice. Many contradictions and problems in the economic and social fields of China are closely related to the imperfect institutions, imperfect legal systems and ineffective implementation of the institutions and legal systems. By changing the way of economic development, changing people's world outlook and values, and innovating the mode of power operation, ecological civilization will guide the development mode of China to transform in a multi-level and multi angle way. The communiqu of the third plenary session of the 18th CPC Central Committee Conference pointed out that, we must promote the modernization of national governance system and improve the governance capacity when comprehensively deepen the reform. In traditional management theories, the government serves as the active subject, while the society serves as the passive object. The relationship between the government and society is the principal subordinate relationship. But the innovate social governance advocates the equal relationship between government and society; both of them are subjects of the modern market. In that process, the government should set up modern service concepts, and put the construction of ecological civilization into the works of ideology, system construction, resource integration and benefit coordination, in order to effectively build ecological civilization from multiple channels.

\subsection{The role of government in the construction of ecological civilization.}

The process of improving ecological rationality is a major social change and collective action, which requires the establishment of new action and cooperation rules among social members, namely the construction of ecological civilization system. The basic environmental quality is a kind of public product, which should be provided by the government as a part of basic public service. In other words, it is the unshakable duty of the government to provide environmental products with public service functions. American scholar Samuelson defines public goods as inseparable interest provided for all members of the society; individuals do not need to buy public goods. The interests and services of public goods should shared by all members of the society; no one can monopolize public goods. Public goods are represented as material forms and service forms.

In the process of constructing ecological civilization, the first task is to establish environmental protection regulations which include the legislation of environmental protection laws, environmental impact assessment mechanisms, ecological accountability mechanisms and ecological recovery compensation systems. The aim of these measures is to restrict the behavior of market players through institutionalization, standardization and legalization. Secondly, the government performance assessment system and index mechanism should be innovated. "Green GDP" is a GDP indicator which contains environmental correction parameters. It can motivate and guide the behavior of the government, promote the government to attach importance to ecology and strive to restore the ecology. Thirdly, the government should set up new governance concepts, take the common governance as the basis, seek a wide range of communication among the public departments, private sectors and citizens, and improve the efficiency and quality of ecological governance on justifiable grounds through joint participation, coordinated solution and public responsibility mechanism.

\subsection{The role of citizens in the construction of ecological civilization.}

Citizens are producers and consumers in the context of ecological civilization. As producers, human beings consider the nature as tools and objectives. If people and nature can not advance together, they will in a dilemma. Therefore, it is necessary to change the ecological consumption of the linear non-circular production mode in the past. Ecological environment construction should be considered in the whole process of industrial production; ecological environment optimization should become an index which measures the quality and degree of industrial development; pollution 
prevention and control should run across the whole process of production. Ecological green technologies should be applied to transform the modern industrial production mode, in order to develop green economy, circular economy and low carbon economy. Citizens are also consumers. Since the reform and opening up, the consumerist lifestyle has been spread in China. However, the lifestyle of consumerism does not bring happiness, but causes health risks. At the same time, the expense of consumerism is the exploitation of natural resources and serious environmental pollution. Ecological civilization is the transcendence of existing civilization; it can guide mankind to abandon the strong utilitarianism and hedonism formed during the period of industrial civilization. The construction of ecological lifestyle is based on the reflection of modern life style. At present, individuals should set up the concept of green consumption, advocate the moderate consumption concept and low-carbon life style, and enjoy the pleasure and comfort of life at the lowest cost. At the same time, citizens should actively participate in the social supervision mechanism on ecological civilization construction, and promote the construction of ecological civilization from the micro level.

\section{References}

[1] K. Marx, Manuscript of Economics and Philosophy in 1844, People's Publishing House, Beijing, 2004.

[2] L. Zhang, et. al, Introduction to Public Administration, SDX Joint Publishing Company, Beijing, 1998.

[3] K. Marx, et. al, Marx, Engels, Lenin and Stalin Translation Office of Central Committee of CPC (Trans), People’s Publishing House, Beijing, 2007.

[4] M.H. Chen, The Prospect of Ecological Culture and Civilization, Wuhan Publishing House, Wuhan, 1995.

[5] Z.G. Xing, L.R. Shi, Social class differences in environmental attitudes: an empirical analysis based on the comprehensive social survey of China in 2005, Journal of Northwest Normal University (Social Science Edition), 6 (2012). 